\title{
The Effect of In Utero Insulin Exposure on Tissue Iron Status in Fetal Rats ${ }^{1}$
}

\author{
MICHAEL K. GEORGIEFF, RICHARD J. KASSNER, WILLIAM J. RADMER, DENNIS J. BERARD \\ SONAL R. DOSHI, AND BARBARA S. STONESTREET \\ Division of Neonatology, Department of Pediatrics, University of Minnesota School of Medicine, \\ Minneapolis, Minnesota 55455 [M.K.G., W.J.R.]; and Division of Neonatology, Department of Pediatrics, \\ Brown University, Providence, Rhode Island 02905-2499 [R.J.K., D.J.B., S.R.D., B.S.S.]
}

\begin{abstract}
Newborn infants of diabetic mothers have serum biochemical signs of iron deficiency in cord blood directly related to elevations of cord erythropoietin and $\mathrm{Hb}$ concentrations. In sheep, chronic fetal hyperinsulinemia results in fetal hypoxemia, expansion of the red cell mass, and decreased iron concentrations, most likely due to increased iron utilization for $\mathrm{Hb}$ synthesis. To determine whether fetal insulin exposure also results in reduced tissue iron concentrations, we measured liver, skeletal muscle, small intestine, heart, and brain iron concentrations in newborn rat pups after s.c. fetal injection of insulin or diluent alone on d 19 of gestation. The fetuses of 11 pregnant rats were exteriorized, injected with $2 \mathrm{U}$ neutral protamine Hagedorn insulin or diluent, replaced in utero, and delivered on d 22. To determine dose dependency, the fetuses of six pregnant rats were injected with $3 \mathrm{U}$ of longer-acting protamine zinc insulin and delivered on $\mathrm{d} 21$. At delivery, the insulin-treated groups had higher birth weights than the placebo-treated group, although plasma insulin concentrations were not different. The $2 \mathrm{U}$ neutral protamine Hagedorn insulin-treated fetuses had significantly lower mean \pm SEM liver iron concentrations than the control fetuses $(910 \pm 34$ versus $1014 \pm 43 \mu \mathrm{g} / \mathrm{g}$ dry tissue weight; $p<0.05$ ), but had similar skeletal muscle iron concentrations. The $3 \mathrm{U}$ protamine zinc insulin-treated fetuses had significantly lower liver and skeletal muscle iron concentrations compared to control and to $2 U$ neutral protamine Hagedorn insulin-treated fetuses $(p<0.05)$. No differences in small intestine, heart, or brain iron concentrations were seen among groups. We conclude that exposure of fetal rats to insulin during late gestation compromises liver and skeletal muscle iron content. Based upon these findings, we speculate that infants of poorly controlled diabetic mothers may be at risk for decreased tissue iron content. (Pediatr Res 31: 64-67, 1992)
\end{abstract}

\section{Abbreviations}

$\mathrm{NPH}$, neutral protamine Hagedorn insulin $\mathrm{PZI}$, protamine zinc insulin

Infants of diabetic mothers are frequently born with serum biochemical signs characteristic of iron deficiency including low

Received April 16, 1991; accepted August 9, 1991.

Correspondence: Barbara S. Stonestreet, M.D., Women and Infants Hospital of Rhode Island, 101 Dudley Street, Providence, RI 02905-2499.

Supported by grants from Ross Laboratories (M.K.G.) and by the National Institutes of Health and Human Development Diabetes Center Grant P-50 HD11343 (B.S.S.).

' Presented in part at the annual meeting of the Society for Pediatric Research, April 30, 1991, in New Orleans, LA. serum iron and ferritin concentrations and elevated transferrin and free erythrocyte protoporphyrin concentrations (1-3). The severity of these abnormalities is inversely related to the mother's glycemic control during pregnancy, and is directly related to the degree of macrosomia at birth and elevations of cord blood erythropoietin and $\mathrm{Hb}$ concentrations (3). Using chronically catheterized fetal sheep, we have previously shown that in utero hyperinsulinemia causes fetal hypoxia, compensatory expansion of the red cell mass, and low serum iron concentrations, most likely due to increased iron utilization for $\mathrm{Hb}$ synthesis $(4,5)$.

Although abnormal plasma iron indices have been documented in infants of diabetic mothers and hyperinsulinemic fetal sheep, their tissue iron status has not been directly assessed. Indirect estimates of total body iron in infants of diabetic mothers with significant serum iron abnormalities at birth suggest that they may have reduced nonhepatic as well as hepatic tissue iron content (3).

The purpose of this study was to determine whether exogenous insulin administration to late gestation fetal rats results in reduced hepatic and nonhepatic tissue iron content. We varied the dosage and duration of action of the insulin to assess whether a relationship exists between the magnitude and duration of fetal insulin exposure and subsequent reductions in tissue iron content. Based upon the differential sensitivity of postnatal rat tissues to iron deficiency (6), we hypothesized that, in the fetal rat liver iron would decrease before skeletal muscle, which in turn would be reduced before heart and brain iron concentrations.

\section{MATERIALS AND METHODS}

Animal preparation. Seventeen time-dated pregnant SpragueDawley rats (Charles River Breeding Laboratories, Wilmington, MA) were used. All rats were individually housed in wood-chipbedded plastic cages in a temperature-controlled, light-dark cycled room and allowed free access to an iron-sufficient stock diet. On d 16 of gestation, $20 \%$ dextrose solution was substituted for water as the sole drinking water to prevent maternal hypoglycemia, which has been observed to result in the demise of the mother $(7,8)$. Five $\mathrm{mg}$ of progesterone was injected intramuscularly daily for $3 \mathrm{~d}$, on d 17 to 19 of gestation, to maintain the pregnancy (8).

A laparotomy was performed under light ketamine anesthesia to exteriorize the fetuses on d 19 of gestation as previously described $(7,8)$. Eleven animals had their fetuses alternately injected along the uterine horn through the uterine wall s.c. into the fetal back with either 2 U NPH (Eli Lilly Co., Indianapolis, IN) in $0.05 \mathrm{~mL}$ of diluent or an equal volume of diluent. Six animals had their fetuses injected with either 3 U PZI (Eli Lilly Co.) or diluent alone. The fetuses were replaced in utero, the laparotomies closed, and gestation allowed to proceed. The fetuses were delivered surgically on d 21 (3 U PZI group) or d 22 
(2 U NPH group), and the number of surviving fetuses was noted. A total of 33 experimental and 32 control fetuses were delivered in the $3 \mathrm{U}$ PZI study and 53 experimental and 57 control pups in the 2 U NPH study. The fetuses were killed and weighed, and truncal blood was obtained for plasma iron and insulin concentrations. Fetal liver, skeletal muscle, small intestine, heart, and brain were washed free of blood in isotonic saline and weighed wet. Organs from insulin-treated fetuses from each mother were pooled, as were tissues from placebo-treated fetuses.

Biochemical assessments. Plasma iron was determined spectrophotometrically using the chromophore Ferene (Dimension Clinical Chemistry, E.I. DuPont Co., Wilmington, DE) as previously described $(2,3)$. Tissue iron samples were lyophilized and weighed dry, and the iron was digested in $10 \mathrm{~mL}$ of $4: 1$ nitric-perchloric acid at $25^{\circ} \mathrm{C}$ for $24 \mathrm{~h}$. After tissue digestion was complete, the iron content was assayed by atomic absorption spectrometry (9). Plasma insulin concentrations were determined by a double RIA (10). The interassay variability was $<5 \%$ for plasma and tissue iron measurements.

Statistical assessment. Tissue and plasma concentrations from the insulin-treated fetuses were compared to those of the placebotreated fetuses using two-tailed paired $t$ tests. To assess whether the combination of increasing both the dose and duration of insulin would affect tissue iron concentrations, two-way analysis of variance using insulin strategy and treatment versus placebo as independent factors was used with post-hoc paired $t$ tests to assess significant differences between group means. Comparisons were considered significant at $p<0.05$. All values are presented as mean $\pm \mathrm{SEM}$.

\section{RESULTS}

The fetuses treated with $2 \mathrm{UNPH}$ weighed slightly, but not significantly, more than diluent-treated fetuses after death, whereas fetuses treated with 3 U PZI weighed significantly more than their respective diluent-treated controls (Table 1). Liver weight was significantly greater in the high-dose insulin group compared to its control group, but no differences in brain or heart weights were observed at either dose (Table 2). Plasma insulin and iron concentrations were not different between experimental and placebo groups at the time of death with either insulin dose (Table 3).

Liver iron concentrations were significantly lower in both insulin-treated groups compared to their respective diluenttreated controls (Fig. 1). In addition, the liver iron concentration of the $3 \mathrm{U}$ PZI group was significantly lower than that in the 2 U NPH group. Skeletal muscle iron concentrations were lower than control only in the $3 \mathrm{U}$ PZI group (Fig. 2). Intestine, heart, and brain iron concentrations were not affected by either insulin dose (Table 4).

Table 1. Fetal weights at delivery

\begin{tabular}{cccc}
\hline Insulin dose & $\begin{array}{c}\text { Gestational age } \\
\text { at delivery }(\mathrm{d})\end{array}$ & $\begin{array}{c}\text { Placebo-treated } \\
\text { wt }(\mathrm{g})\end{array}$ & $\begin{array}{c}\text { Insulin-treated } \\
\text { wt }(\mathrm{g})\end{array}$ \\
\hline 2 U NPH & 22 & $5.59 \pm 0.20$ & $5.68 \pm 0.16$ \\
3 U PZI & 21 & $5.85 \pm 0.43$ & $6.16 \pm 0.58^{*}$ \\
\hline
\end{tabular}

${ }^{*} p<0.05$ compared to placebo.

Table 2. Fetal organ wet weights at delivery

\begin{tabular}{cccc}
\hline & & \multicolumn{2}{c}{ Organ wt (g) } \\
\cline { 3 - 4 } Organ & Insulin dose & Placebo-treated & Insulin-treated \\
\hline Liver & 2 U NPH & $0.27 \pm 0.01$ & $0.29 \pm 0.01$ \\
& 3 U PZI & $0.28 \pm 0.01$ & $0.31 \pm 0.02^{*}$ \\
Heart & 2 U NPH & $0.04 \pm 0.003$ & $0.04 \pm 0.004$ \\
& 3 U PZI & $0.04 \pm 0.006$ & $0.04 \pm 0.002$ \\
Brain & 2 U NPH & $0.21 \pm 0.01$ & $0.22 \pm 0.01$ \\
& 3 U PZI & $0.19 \pm 0.02$ & $0.21 \pm 0.01$ \\
\hline
\end{tabular}

${ }^{*} p<0.05$ compared to placebo.
Table 3. Plasma iron and insulin concentrations at delivery Concentration

Insulin dose Placebo-treated Insulin-treated

\begin{tabular}{llcc}
\hline Plasma iron $(\mu \mathrm{M} / \mathrm{L})$ & $2 \mathrm{U} \mathrm{NPH}$ & $53.7 \pm 3.9$ & $50.1 \pm 7.3$ \\
& $3 \mathrm{U} \mathrm{PZI}$ & $42.2 \pm 6.6$ & $45.2 \pm 12.4$ \\
Plasma insulin $(\mathrm{pmol} / \mathrm{L})$ & $2 \mathrm{U} \mathrm{NPH}$ & $1479.5 \pm 169.3$ & $1476.6 \pm 160.0$ \\
& $3 \mathrm{U} \mathrm{PZI}$ & $73.2 \pm 5.7$ & $170.8 \pm 95.4$ \\
\hline
\end{tabular}

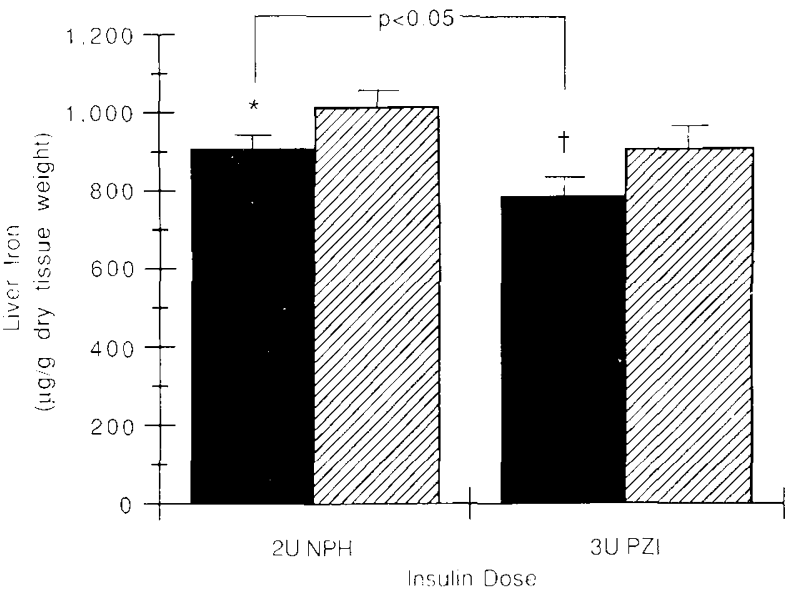

Fig. 1. Liver iron concentrations in insulin-( $\mathbf{\square})$ and placebo-treated (2) fetal rats. *, significant at $p<0.05 ; \dagger$, significant at $p<0.01$ when compared to the respective placebo group. Values are mean \pm SEM.

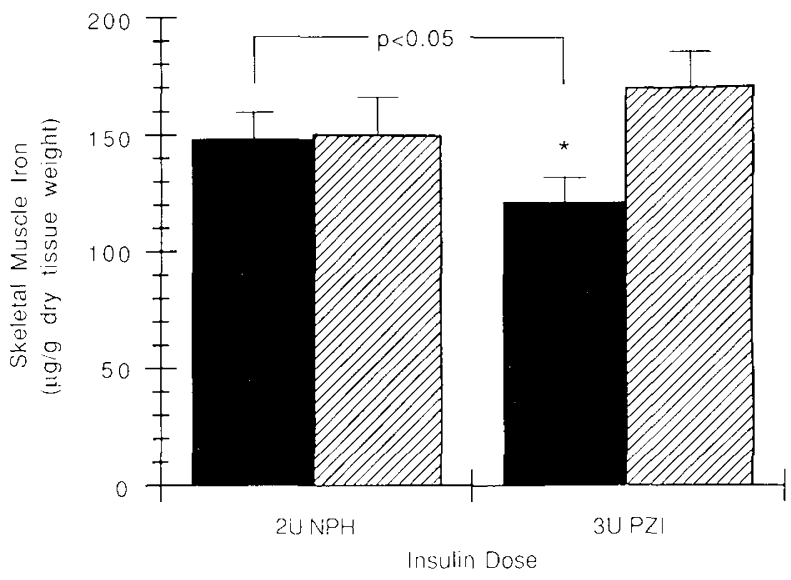

Fig. 2. Skeletal muscle iron concentrations in insulin-(ם) and placebo-treated (绝) fetal rats. ${ }^{*}$, significant at $p<0.05$ compared to placebo. Values are mean \pm SEM.

Table 4. Small intestine, heart, and brain iron concentrations at delivery

\begin{tabular}{lccc}
\hline & & \multicolumn{2}{c}{ Iron concentrations $(\mu \mathrm{g} / \mathrm{g}$ dry wt $)$} \\
\cline { 3 - 4 } & Insulin dose & Placebo-treated & Insulin-treated \\
\hline \multirow{2}{*}{ Small intestine } & $2 \mathrm{U} \mathrm{NPH}$ & $98.6 \pm 6.7$ & $121.3 \pm 11.8$ \\
\multirow{3}{*}{ Heart } & $3 \mathrm{U} \mathrm{PZI}$ & $101.3 \pm 5.3$ & $90.1 \pm 7.4$ \\
& $2 \mathrm{U} \mathrm{NPH}$ & $276.6 \pm 19.7$ & $303.2 \pm 14.2$ \\
Brain & $3 \mathrm{U} \mathrm{PZI}$ & $230.4 \pm 16.8$ & $271.0 \pm 15.0$ \\
& $2 \mathrm{U} \mathrm{NPH}$ & $199.4 \pm 12.5$ & $174.7 \pm 6.1$ \\
& $3 \mathrm{U} \mathrm{PZI}$ & $166.0 \pm 19.8$ & $160.1 \pm 13.7$ \\
\hline
\end{tabular}

\section{DISCUSSION}

This study demonstrated that exposure of fetal rats to excess insulin during late gestation results in a reduction of hepatic and skeletal muscle iron concentrations. Our findings, when consid- 
ered in conjunction with our previous observations of decreased plasma iron concentrations during hyperinsulinemia-induced erythropoiesis in fetal sheep (4), suggest that late gestation hyperinsulinism results in a reduction of plasma and tissue iron content in the fetus to provide iron needed for red cell mass expansion (5). These two models potentially explain the abnormal plasma iron status found in infants of poorly controlled diabetic mothers at birth $(1-3)$ and raises the possibility that these infants may be at risk for reduced tissue iron content as well.

We and others have demonstrated that hyperinsulinemia causes significant arterial hypoxemia $(4,5,11)$, most likely because of increased cellular oxygen consumption (11). The resultant compensatory expansion of the red cell mass, which we have documented in fetal sheep $(4,5)$ and which is characterized by polycythemia in infants of diabetic mothers (12), necessitates an increase in iron delivery to the bone marrow for $\mathrm{Hb}$ synthesis. This increased iron use is thought to result in the reduced plasma iron concentrations, which we have documented in fetal sheep and newborn infants of diabetic mothers (2-4). Infants of diabetic mothers also have abnormally low ferritin concentrations at birth (1-3), an indirect indication of decreased hepatic iron storage. There is, however, no plasma marker in humans reflecting nonstorage tissue iron content. Thus, the nonhepatic tissue iron content of poorly controlled infants of diabetic mothers is unknown.

The present study provides direct tissue evidence demonstrating an association between fetal insulin exposure and decreased tissue iron content. Both groups of insulin-treated rat fetuses had decreased hepatic iron concentrations, indicating a reduction in liver iron stores. There appeared to be a slightly greater hepatic iron response in the group injected with $3 \mathrm{U}$ PZI, suggesting that longer exposure to a higher insulin dose results in a greater reduction in hepatic iron stores. The PZI-treated fetuses had lower skeletal muscle iron content than placebo-injected fetuses, whereas there was no difference in muscle iron content between insulin- and placebo-injected animals when a lower dose of a shorter acting insulin (NPH) was used.

Unlike liver and skeletal muscle, small intestine, heart, and brain iron content were not affected by either experimental condition. The differential response across tissues is consistent with models of dietary iron deficiency in the postnatal rat (6). In that model, as iron deficiency progresses, hepatic iron stores are mobilized initially (13). Skeletal muscle and small intestine iron concentrations decrease only after liver iron has been compromised. Brain and heart are relatively resistant to iron deficiency states $(6,14)$. A similar sequence appears to occur in the fetal rat exposed to excess insulin, with the exception that the small intestine was resistant to both doses of insulin. Our study demonstrates that more severe and/or longer duration of insulin exposure is needed to compromise skeletal muscle iron compared with liver iron in the rat.

The constraints of this model precluded continuous plasma monitoring, which was possible in fetal sheep. Because we did not monitor arterial oxygen saturation or erythropoietic response in the fetuses, we can only surmise that events similar to those documented in fetal sheep $(4,5)$ took place in the rat in response to insulin loading. We did not find higher insulin concentrations in the insulin-treated groups at the time of death. Nevertheless, it is quite likely that differences in insulin concentrations did exist, inasmuch as the insulin-treated fetuses were macrosomic relative to control, particularly in the PZI-treated group. Given the relatively short half-lives of both NPH and PZI (24 and 36 $h$, respectively, in humans), it is likely that the exogenous insulin administered to the metabolically more active rat was fully metabolized by the time of death.

It was not possible to compare plasma insulin concentrations at the time of death between the two insulin-treated groups or the two placebo-treated groups at different days of gestation. Plasma insulin concentrations vary considerably between $\mathrm{d} 21.5$ and 22.5 of gestation in the rat, with previous studies documenting a range of mean values from 37.9 to $199 \mu \mathrm{U} / \mathrm{mL}(8,15-17)$. Sodoyez-Goffaux et al. (17) demonstrated a surge in plasma immunoreactive insulin concentrations after d 19 of gestation and a large variability noted particularly after $\mathrm{d} 20$. The values for our animals at each gestational age were in the same range as those documented by previous investigators $(15,17)$.

There were also no differences in plasma iron concentrations at the time of death. Once again, it is likely that we did not sample at the nadir of the plasma iron response, although some 3 U PZI-treated fetal samples showed a residual effect, accounting for the large SEM seen in that group. In fetal sheep, acute erythropoietin administration results in a transient decrease in plasma iron concentrations (18), whereas persistent hyperinsulinemia chronically suppresses iron levels (4). We speculate that plasma iron concentrations in the insulin-treated rats decreased transiently in response to the acute insulin dose but recovered by the time of study termination.

This study confirms that exposure of fetal rats to exogenous insulin during late gestation compromises liver and skeletal muscle iron content while leaving brain, heart, and small intestine iron content intact. In muscle, iron is localized in heme proteins such as myoglobin, cytochromes, and catalase and in enzymes such as succinate dehydrogenase, monoamine oxidase, and $\alpha$-glycerophosphate oxidase (19). Postnatal models suggest that decreased concentrations of these compounds are responsible for the physiologic dysfunction seen in iron deficiency states (20-22). If applicable to the human fetus, we speculate that these results provide evidence that infants of poorly controlled diabetic mothers exposed to chronic hyperinsulinemia may be at risk for reduction of hepatic and nonhepatic tissue iron.

Acknowledgments. The authors thank Marla Mills and Lucy Wong for technical assistance.

\section{REFERENCES}

1. Chockalingam UM, Murphy E, Ophoven JC, Weisdorf SA, Georgieff MK 1987 Cord transferrin and ferritin values in newborn infants at risk for prenatal uteroplacental insufficiency and chronic hypoxia. J Pediatr 111:283-286

2. Amarnath UM, Ophoven JJ, Mills MM, Murphy EL, Georgieff MK 1989 The relationship between decreased iron stores, serum iron and neonatal hypoglycemia in large-for-dates newborn infants. Acta Paediatr Scand 78:538543

3. Georgieff MK, Landon MB, Mills MM, Hedlund BE, Faassen AE, Schmidt RL, Ophoven JJ, Widness JA 1990 Abnormal iron distribution in infants of diabetic mothers: spectrum and maternal antecedents. J Pediatr 117:455461

4. Georgieff MK, Widness JA, Mills MM, Stonestreet BS 1989 The effect of prolonged intrauterine hyperinsulinemia on iron utilization in fetal sheep. Pediatr Res 25:467-469

5. Stonestreet BS, Goldstein M, Oh W, Widness JA 1989 Effects of prolonged hyperinsulinemia on erythropoiesis in fetal sheep. Am J Physiol 257:R1199R1204

6. Dallman PR 1986 Biochemical basis for the manifestations of iron deficiency. Annu Rev Nutr 16:13-40

7. Vileisis RA, Oh W 1983 Enhanced fatty acid synthesis in hyperinsulinemic rat fetuses. J Nutr 113:246-252

8. Catlin EA, Cha C-JM, Oh W 1985 Postnatal growth and fatty acid synthesis in insulin-induced macrosomic rat pups. Metabolism 34:1110-1114

9. Kreeftenberg HG, Koopman BJ, Huizenga JR, van Vilsteren $\mathrm{T}$, Wolthers BG, Gips CH 1984 Measurement of iron in liver biopsies: a comparison of three analytical methods. Clin Chem Acta 144:255-262

10. Hales CN, Randle PH 1963 Immunoassay of insulin with insulin antibody precipitates. Biochem J 88:137-146

11. Milley JR, Papacostas JS, Tabata BK 1986 Effect of insulin on uptake of metabolic substrates by the fetus. Am J Physiol 231:E349-E359

12. Mimouni F, Miodovnik M, Siddiqi TA, Butler JB, Holdroyde J, Tsang RC 1986 Neonatal polycythemia in infants of diabetic mothers. Obstet Gynecol 69:370-372

13. Huebers HA 1989 Iron metabolism: iron transport and cellular uptake mechanisms. In: Lonnerdal B (ed) Iron Metabolism in Infants. CRC Press, Boca Raton, FL, pp $1-32$

14. Ben-Sachar D, Ashkenazi R, Youdim MBH 1986 Long-term consequences of early iron-deficiency on dopaminergic neurotransmission. Int J Dev Neurosci 4:81-88

15. Watts C, Gain K, Sandin PL 1976 Glucose homeostasis in the developing rat Biol Neonate 30:88-94 
16. Girard JR, Kervran A, Soufflet E, Assan R 1974 Factors affecting the secretion of insulin and glucagon by the rat fetus. Diabetes 23:310-317

17. Sodoyez-Goffaux FR, Sodoyez JC, De Vos CJ 1979 Insulin secretion and metabolism during the perinatal period in the rat. J Clin Invest 63:10951102

18. Georgieff MK, Schmidt RL, Mills MM, Widness JA 1990 Erythropoiesis and iron status during prolonged fetal hypoxemia. Pediatr Res 27:264A(abstr)

19. Huebers HA 1989 Nonhematological manifestations of iron deficiency. In: Lonnerdal B (ed) Iron Metabolism in Infants. CRC Press, Boca Raton, FL, pp 64-72
20. Ohira Y, Hegenauer J, Strause L, Chen C-S, Saltman P, Beinert H 1982 Mitochondrial NADH dehydrogenase in iron-deficient and iron-repleted rat muscle: an EPR and work performance study. Br J Haematol 52:623-630

21. Blayney L, Royston B-W, Jacobs A, Henderson A, Muir J 1976 The effects of iron deficiency on the respiratory function and cytochrome content of rat heart mitochondria. Circ Res 39:744-748

22. Mackler B, Grace R, Finch CA 1984 Iron deficiency in the rat: effects on oxidative metabolism in distinct types of skeletal muscle. Pediatr Res 18:499500

\section{Announcement 1992 Annual Meetings}

The American Pediatric Society, The Society for Pediatric Research, and The Ambulatory Pediatric Association will hold their annual meetings May 4-7, 1992 at the Baltimore Convention Center, Baltimore, MD. For further information, contact: APS/SPR Association Headquarters, 141 Northwest Point Blvd., P.O. Box 675, Elk Grove Village, IL 60009-0675, (708)427-0205, FAX (708)427-1305 or Ambulatory Pediatric Association, 6728 Old McLean Village, McLean, VA 22101, (703)556-9222. 